\title{
Osteopathic hospital affiliations with multi-hospital systems: Guidelines for negotiations
}

\author{
WILLIAM G. ANDERSON, D.O. \\ Southfield, Michigan \\ GEORGE A. REUTHER \\ Chicago, Illinois
}

\begin{abstract}
Osteopathic hospitals are becoming increasingly more involved in multi-hospital systems. Those institutions entering such affiliations can help to ensure their continuing success through careful negotiation of lease/purchase or management agreements. To investigate this area of health care and its impact on the osteopathic medical profession, the American Osteopathic Association established a Task Force on Proprietary Multi-Hospital and Other Multi-Hospital Systems. This paper lists the conclusions of that Task Force and its recommendation of important points to be used as a framework for negotiations between osteopathic hospitals and multi-hospital systems.
\end{abstract}

\section{Industry background}

The hospital industry has been forced to assess its methods of financing and reshape its operations from a cost-plus system of reimbursement to a limited and decreasing reimbursement system that demands more efficient utilization of health care resources with fewer dollars. This has become one of the most formidable tasks that the industry has had to endure.

Among the measures taken by the hospital industry to meet this challenge is a movement toward consolidation of its existing facilities and expansion to broaden its base. To this end, previously independent hospitals have formed corporations to expand or merge with other hospital corporations or have been acquired by them. This is a growing trend, and it has been forecasted that, within the next decade, the majority of hospitals in the United States will be part of a few major hospital systems.

\section{Establishment of AOA Task Force}

Osteopathic hospitals are particularly attractive targets for merger or acquisition for a variety of reasons including the strong family practice base and the osteopathic certificate of need among others. There is a growing awareness that such changes in management may not give enough consideration to the desire on the part of osteopathic physicians to maintain the identity, goals, and accreditation of these osteopathic institutions. It is essential to preserve these features. To obtain this objective, in February 1986, the president of the American Osteopathic Association appointed a Task Force on Proprietary Multi-Hospital and Other Multi-Hospital Systems. It was to review the extent of involvement of osteopathic hospitals with multi-hospital groups, and to develop guidelines for proprietary and other multi-hospital operation of osteopathic hospitals, to aid in the preservation of osteopathic identity, accreditation, practice rights, and training programs.

The Task Force reviewed existing literature to gain a national perspective on the major issues it would need to address. To assess the impact of affiliation with multi-hospital systems on osteopathic institutions, a questionnaire was mailed to osteopathic hospitals that had internship and residency programs and also were either owned or managed by a multi-hospital system. Finally, several existing contracts between osteopathic facilities and multi-hospital systems were reviewed, and key staff from these institutions were consulted for their views in regard to negotiating such agreements.

\section{Task Force conclusions}

The Task Force drew four major conclusions from these reviews:

(1) Multi-hospital systems have developed in both the for-profit and the not-for-profit sector and have been expanding rapidly for many years. These affiliations have resulted from strategies designed to provide access to additional capital and a wider pool of administrative, managerial, and marketing expertise on which individual institutions may draw. National trends indicate that the movement toward multi-hospital systems, both for-profit and not-for profit, will continue.

(2) In this atmosphere of competition and merger, osteopathic hospitals will experience increasing pressure to affiliate with multi-hospital systems. 
Indeed, 37 percent (73 of 195) of the osteopathic hospitals listed in the 1986 Annual Directory of the American Osteopathic Hospital Association are already involved with various multi-hospital systems at local, regional, and national levels. For the most part, they have fared well.

(3) According to the thirty osteopathic hospitals that responded to the Task Force survey, joining multi-hospital systems has had a generally positive effect. There have been some problems but also definite gains. For example, the number of osteopathic physicians recruited has increased and the number of clinical clerkships, internships, and residencies has expanded. The financial viability of several osteopathic institutions has been improved.

(4) As expected, in many of the hospitals much of the authority of the local board of trustees has been lost to the corporate board of trustees. These corporate boards and the multi-hospital systems that they represent have been very supportive of the desire on the part of osteopathic facilities to preserve their identity, mission, and programs in some cases. However, such positive activities by multihospital systems cannot be guaranteed in the future without careful contract negotiation. It is imperative, therefore, that safeguards be built into contracts between osteopathic hospitals and multihospital systems to protect and preserve osteopathic ideals. Establishment of a trust fund is an important vehicle for helping to guarantee compliance with these contracts.

It is with these understandings in mind that the Task Force prepared its recommendations.

\section{Recommendations}

The Task Force developed a summary listing of important points that it believed should be a part of any negotiations between osteopathic hospitals and multi-hospital systems, whether those negotiations cover management contracts, leases, or purchases. This list was not intended to be all inclusive, but rather to provide a framework or base from which to begin. It covers maintenance of osteopathic identity, mission, and training programs. These guidelines are based on existing contract arrangements reviewed by the Task Force.

\section{Important points for contract negotiations}

\section{General principles}

Prior to entering negotiations with a multi-hospital system an osteopathic health care facility should address these principles.

(1) The spirit and intent of negotiations must be covered in the written agreements.

(2) Osteopathic physicians of the health care facility must be in total support of the agreements or those agreements will fail.

(3) The health care facility must provide an oversight function through which it can monitor the multi-hospital system's compliance with the negotiated agreements. The individuals performing the oversight must be qualified to perform their functions and have the authority to gather data and materials necessary to conduct their work.

(4) If consideration of an affiliation becomes necessary because of financial problems, the hospital should not delay entering into negotiations until it is in a very weakened position.

(5) The representatives of the corporation with which the osteopathic facility is negotiating must have the professional expertise to deal with all areas of that facility, not just some.

(6) The final agreement should provide that the closing of the transaction will be conditioned upon receipt of approvals of all governmental agencies required to effectuate the agreements between the osteopathic health care facility, its board of trustees, and the board of trustees of the corporation.

(7) The maintenance of all patient services must be insisted upon even if they have to be "loss leaders" until revitalized.

(8) If necessary property should be leased rather than sold, because buildings and services can be eliminated by construction projects.

(9) The corporation should agree to provide and ensure the highest quality patient care to the residents of local community and section of the state. (10) The corporation should agree that, to the extent possible, local medical staff issues will be determined at the local governing board level with appropriate input by the corporation and the health care facility.

(11) Operating agreements should include the provision that the corporation will accept the members of the health care facility's medical staff for the balance of their present term, provided that as of closing they are, and at all material times thereafter remain, members in good standing of the facility's medical staff.

\section{Guidelines for maintenance of osteopathic identity}

When a management contract, lease, or purchase agreement is being negotiated, maintenance of the osteopathic identity must be safeguarded. Points to be considered are as follows:

(1) The corporation should agree to recognize that the health care institution is an osteopathic institution and guarantee: a. Maintenance of the image and title "osteopathic;" b. Inclusion of the word "osteopathic" on official signage and letterhead stationery.

(2) The corporation should agree to retain the osteopathic identity of the institution by guarantee- 
ing: a. active affiliation with local, state, and national osteopathic organizations; b. accreditation by the American Osteopathic Association; c. use of its best efforts to remain in good standing with such osteopathic organizations and no voluntary withdrawal from them; $d$. use of its best efforts to recruit osteopathic physicians to join the medical staff; e. appointment of osteopathic physicians as directors of the current departments and for hospital services; $f$. maintenance and funding of any current osteopathic clinical clerkship, internship, and residency programs, and further, as resources become available, seeking the expansion and development of osteopathic predoctoral and postdoctoral training programs.

(3) The corporation should agree to D.O. membership on corporate board of trustees or physicians advisory board, or representation to such board of trustees.

(4) The local board of trustees should have a majority of D.O.s as members.

(5) The corporation should be asked to help fund osteopathic research.

(6) A resolution that they will not discriminate against D.O.s in the multi-hospital system should be obtained from the corporate board of trustees. (7) The corporation should agree to promote the development of osteopathic hospitals within their corporate structure.

\section{Guidelines for maintenance of osteopathic educa-} tion

The preservation of osteopathic education and training programs is fundamental. To achieve this end, several key elements should be addressed.

(1) Osteopathic teaching hospitals should continue their educational programs with state-of-the-art equipment, appropriate staff, and resources.

(2) The hospital should continue affiliation with other medical and educational facilities that contribute to its predoctoral and postdoctoral training programs.

(3) The agreements should set up scholarship endowments for future osteopathic training positions.

(4) The agreements should require the corporation to provide postgraduate osteopathic medical education salaries for the existing (or number agreed to) intern and resident positions.

\section{Guidelines for elimination of financial risk}

A major reason for negotiating corporate affiliations with multi-hospital systems is to gain financial stability, management expertise, and a stronger capital base. To achieve these ends it is recommended that osteopathic health care facilities:
(1) Seek an agreement to lease or sell the health care facility. Details should be locked in by time frames. During negotiations the facility should be specific, not just state general opinions or desires. It should be sure that the agreement covers all buildings, number and dollar value of all equipment, educational programs, osteopathic identity, etcetera.

(2) When negotiating the sale of any facility equipment be sure to drop all obsolete equipment before determining the price.

(3) State in the contract that the equipment is in as-is condition and assure that responsibility for repairs and maintenance is fixed. A mutual audit of the inventory should be performed to insure agreement and avoid later conflicts.

(4) If the corporation charges for support services already in place within the health care facility structure, such as a purchasing surcharge on each purchase order processed, retain the function within the health care facility structure to avoid bleeding off facility resources to pay for corporate overhead. Corporate purchasing programs, however, may have substantially lower price agreements.

(5) When dollars related to such things as purchase of equipment change hands, put the dollars in trust for the advancement of the osteopathic medical profession.

(6) Establish trust funds as vehicles for funds received from sale or lease of osteopathic hospitals, for use as legal safeguards for preserving osteopathic identity, training programs, and other items negotiated into sale or lease agreements.

(7) Investigate a state loan to fund building programs. A trust fund should be set up for any loans. Trust fund interest should be used to cover a loan from the state and any additional interest earned to pay for building programs.

(8) Own and finance any new construction. The corporation should enter into a long-term lease agreement for such construction equivalent to the remaining term of the master lease. The corporation should assist the facility in arranging for the financing.

(9) Negotiate provisions to cover the cost of malpractice insurance for appropriate students and staff.

(10) See that lease payments made by the corportion are large enough to cover the facility's indebtedness so that the facility may be free of risk in having to arrange for payment.

(11) Ask the corporation to pay a one-time rental equal to the amount finally determined to be the facility's Hill-Burton recapture obligation payable as a result of the facilities entering into the lease agreement. 


\section{Comment}

The trend toward multihospital affiliations in the health care industry is well established. The osteopathic medical profession and its hospitals are not exempt from this trend but in fact are already an integral part of it. Whether we continue to thrive and grow in this climate will in large measure be dependent upon the ability of osteopathic institutions to enter into such affiliations with appropriate care. The preservation of our identity as a distinct profession, the continuance of our training and research programs, and the protection of our rights to provide osteopathic general and specialty medical care is at stake. These interests will only be secured if we exercise extreme diligence and perseverance as the tide of multihospital affiliations sweeps over the health care industry.

Dr. Anderson is chairman of the AOA Task Force on MultiHospital Systems. Mr. Reuther is assistant director of the Divisions of Continuing Medical Education and Hospital Accreditation, AOA Department of Education, Chicago, Illinois. 